\title{
Estudio de la preparación del profesorado en México ante la pandemia del COVID-19 en la transición de enseñanza presencial a virtual o en línea
}

\author{
José Dionicio Zacarias Flores ${ }^{1}$ \\ jzacarias@fcfm.buap.mx \\ https://orcid.org/0000-0003-2431-5341 \\ Gladys Denisse Salgado Suárez ${ }^{2}$ \\ gladys.salgado@udlap.mx \\ https://orcid.org/0000-0001-7549-3346 \\ ${ }^{1}$ Benemérita Universidad Autónoma de Puebla (BUAP, México) \\ ${ }^{2}$ Universidad de las Américas Puebla (UDLAP, México)
}

Recibido: 31/05/2020 Aceptado: 13/07/2020

\begin{abstract}
Resumen
Ante el surgimiento del virus nombrado COVID-19 que llegó a México a finales de febrero del 2020, diversas actividades tuvieron que ser modificadas, entre ellas, el sistema educativo, el cual intentó continuar en un modelo no presencial, obligando a profesores y estudiantes a cambiar a un sistema virtual o en línea. En el presente trabajo se muestra un primer acercamiento de ¿qué tan capacitados estaban los profesores en México para la transición de enseñanza presencial a la enseñanza virtual o en línea?, dicho estudio se realizó a través de una encuesta realizada a profesores de nivel medio superior y superior de diversas instituciones del país. Mediante un análisis estadístico descriptivo se muestran las herramientas tecnológicas en los que ya se encontraban capacitados como son: Facebook, WhatsApp, correo electrónico, y Google Drive, los cuales son solo herramientas de comunicación, pero no como recurso didáctico, ni de soporte ni de seguimiento; en los que necesitaron capacitación son: Zoom, Khan Academy, WhatsApp Web, Google Classroom, Facebook y Microsoft Teams; además del tiempo y esfuerzo realizado en el aprendizaje exprés de ellos, así también, su nivel de manejo, tiempo de preparación (que en promedio se duplicó) y diversas dificultades identificadas en los profesores. Finalmente se muestran las conclusiones a las que llegamos, que nos permitieron dar respuesta a la pregunta de investigación.
\end{abstract}

Palabras claves: Tecnologías digitales; Pandemia; Educación media superior y superior; Enseñanza presencial; Enseñanza virtual; Enseñanza en línea.

\section{Study of the preparation of teachers in Mexico in the face of the COVID-19 pandemic in the transition from face-to-face to virtual or online teaching}

\begin{abstract}
Given the emergence of the virus named COVID-19 that arrived in Mexico at the end of February 2020, various activities had to be modified, including the educational system, which attempted to continue in a non-classroom model, forcing teachers and students to switch to a virtual or online system. This work shows a first approach of how trained were teachers in Mexico for the transition from face-to-face teaching to virtual or online teaching? This study
\end{abstract}


was carried out through a survey of upper-middle-level teachers and superior of various institutions in the country. A descriptive statistical analysis shows the technological tools in which they were already trained, such as: Facebook, WhatsApp, email, and Google Drive, which are only communication tools, but not as a didactic or support resource or tracing; The ones that needed training are: Zoom, Khan Academy, WhatsApp Web, Google Classroom, Facebook and Microsoft Teams; in addition to the time and effort made in their express learning, as well as their level of management, preparation time (which on average doubled) and various difficulties identified by teachers. Finally, the conclusions we reached are shown, which allowed us to answer the research question.

Key words: Digital technologies; Pandemic; Higher education and high school; Classroom teaching; Virtual teaching; Online teaching.

\section{Estudo da preparação de professores no México para enfrentar a pandemia COVID-19 na transição do ensino presencial para o ensino virtual ou online}

\section{Resumo}

Diante do surgimento do vírus denominado COVID-19 que chegou ao México no final de fevereiro de 2020, várias atividades tiveram que ser modificadas, inclusive o sistema educacional, que tentou continuar em um modelo não presencial, obrigando professores e alunos a mudar para um sistema virtual ou online. Este trabalho mostra uma primeira abordagem à forma como qualificado eram professores no México para a transição do ensino face-a-face com o ensino virtual ou online? Estudo disse foi realizada através de uma pesquisa com professores de nível secundário e superior de várias instituições do país. Por meio de uma análise estatística descritiva, são apresentadas as ferramentas tecnológicas nas quais já foram treinados, como: Facebook, WhatsApp, e-mail e Google Drive, que são apenas ferramentas de comunicação, mas não como recurso didático, ou de suporte ou rastreamento; onde eles precisaram de treinamento são: Zoom, Khan Academy, WhatsApp Web, Google Classroom, Facebook e Microsoft Teams; além do tempo e esforço despendidos na aprendizagem expressa, bem como o seu nível de gestão, o tempo de preparação (que em média duplicou) e várias dificuldades identificadas nos professores. Por fim, são apresentadas as conclusões a que chegamos, o que nos permitiu responder à questão de pesquisa.

Palavras-chave: Tecnologias digitais; Pandemia; Ensino médio e superior; Ensino presencial; Ensino virtual; Ensino online.

\section{Introducción}

A principios de este año 2020 (28 de febrero) llegó a México el virus COVID-19, que obligó al país a detener la mayoría de sus actividades, dejando en activo solo a las actividades esenciales. Una de las actividades que se detuvo fue la educación presencial por no ser esencial en tiempos de pandemia. Posteriormente, la Secretaría de Educación Pública (SEP) extendió el período vacacional escolar del 23 de marzo al 17 de abril del 2020, aunque al final lo volvió a 
extender hasta el 30 de abril del 2020. La manera en la que se ha tratado de afrontar el desafío de continuar con la enseñanza en todos los niveles educativos, de acuerdo con la SEP, es haciendo un cambio de educación presencial a educación virtual o en línea.

La enseñanza que se recibe comúnmente en un salón de clases (educación presencial) se da por medio de la transmisión de conocimientos orales, mediante la interacción implícita o explícita entre el profesor, los alumnos y su entorno, con el objetivo de lograr el aprendizaje, desde el punto de vista piagetiano, que se construya el conocimiento, esto es lo que Brousseau (2006) llama una situación didáctica. Pero existe además la situación a-didáctica en la que el alumno asume el rol principal y se vuelve autónomo creando por sí mismo el conocimiento, no con la intención de satisfacer al profesor sino por el aprendizaje mismo. Esta última es la que en estos tiempos de pandemia puede ayudar a la transición a educación virtual y/o en línea.

La educación virtual es un proceso formativo sincrónico o asincrónico, cuya característica principal es el de apoyarse en el uso de Internet, pues, como lo mencionan Suárez y Anaya (2004), permite el uso de plataformas educativas (Blackboard, Moodle, Google Classroom, etc.), foros, correos electrónicos, páginas Web, videoconferencias, etc.

La educación en línea es un proceso formativo en el que especialistas, docentes y estudiantes participan de manera remota, mediante el uso de Internet y el de las Tecnologías de Información y Comunicación (TIC), en tiempo real, a cualquier hora y desde cualquier lugar (Gallardo, 2007).

Se entiende por TIC al "conjunto de procesos y productos derivados de las nuevas herramientas (hardware y software), soportes de la información y canales de comunicación relacionados con el almacenamiento, procesamiento y transmisión digitalizados de la información" (Adell, 1997, p.34). Entre las ventajas del uso de las TIC están sus posibilidades educativas, es decir, la diversidad de funcionalidades, como son (Marquéz, 2001):

- Pizarra digital en el aula de clase.

- Web de centro, de los profesores, de la asignatura y de los alumnos.

- Centros virtuales de recursos temáticos.

- Portafolios virtuales.

- Plataformas e-centro.

- Tutorías virtuales. 
- Foros virtuales.

- Comunidades virtuales y comunidades de aprendizaje.

- Actividades de aprendizaje colaborativo en red.

- Videoconferencias.

Así también, las tecnologías se vuelven verdaderamente útiles para crear ambientes de aprendizaje más flexibles, rompiendo las brechas espacio-temporales que permiten nuevas modalidades educativas que pueden contribuir al aprendizaje significativo (Monzón, 2020). Sin embargo, existen diversas dificultades en el cambio educativo. En el sentido profesional, se requiere de mucho trabajo docente previo, la preparación y evaluación de las clases, que incluye elaboración de actividades, problemas, cuestionarios, etc., de manera que puedan ser abordados, discutidos y aprendidos por el alumno (pero sin el docente). La introducción de estas prácticas didácticas no es sencilla porque va en contra de lo que usualmente se ha hecho a lo largo del tiempo, tanto docentes como estudiantes están acostumbrados a la metodología tradicional de atender la explicación del docente y romper con este sistema es difícil (Zipitría, 2020) aunado con el conocimiento necesario para la implementación de las TIC en la práctica pedagógica.

Respecto a la infraestructura, la tecnología digital nos ha alcanzado, pero no todas las personas tienen acceso a las TIC ni en recursos ni en conocimientos. Según el comunicado oficial realizado por el Instituto Nacional de Estadística, Geografía e Información (INEGI) en febrero de 2020 con respecto a los usuarios de las TIC, muestra que el 76.6\% de la población urbana es usuaria de Internet, en la zona rural la población usuaria se ubica en 47.7\%. En los hogares del país, el $44.3 \%$ dispone de computadora, el $92.5 \%$ cuenta con al menos un televisor (INEGI, 2020). Pero en familias donde los padres necesitan las TIC para su trabajo y hay más de un estudiante, una computadora no es suficiente para toda la familia, de manera similar, que pasa con ese $24.4 \%$ de la población urbana y ese $53.3 \%$ de la población rural que no tiene acceso a Internet, es aquí donde el reto de enseñar y aprender es aún más grande, y donde los derechos de los estudiantes son violentados al eliminar de tajo el término “educación para todos" (Peñate, 2020).

En el sentido digital, el analfabetismo digital, es el desconocimiento de los avances digitales y las nuevas tecnologías (Guaña et al., 2016). Debido a que la contingencia del COVID19 sucedió de manera inesperada, es posible que no haya habido tiempo suficiente para una 
capacitación adecuada de los recursos digitales en los profesores, lo que mostraría que el profesor no estaba preparado para la enseñanza en línea (Monzón, 2020). Hoy en día, existe diversidad de investigaciones que nos muestran el poco o mucho uso de las tecnologías educativas, igualmente hay diversidad de trabajos que estudian la formación de los docentes en el uso de las TIC. Demos un vistazo a uno de los trabajos para conocer el impacto que está teniendo el uso de las TIC en la enseñanza.

En el trabajo de Mirete (2010), se hace una revisión a las causas del porqué al profesorado se le dificulta realizar la incorporación de las tecnologías digitales en su labor de docencia, realizando la siguiente pregunta: Si queremos introducir las TIC en el aula, ¿Dónde están las dificultades? En primera instancia se parte del hecho de que la institución tiene los recursos tecnológicos para lograr hacer la introducción de las TIC a las aulas. Después deben incorporarse a las aulas, de tal manera de que no sean más un problema que una solución. Es decir, debe investigarse que su uso sea casi transparente en el trabajo habitual del docente y del alumnado. Se logrará cuando el profesor tenga la formación apropiada en el uso de las tecnologías básicas, ¿la tendrá? No sólo como recurso didáctico, sino también como recurso de soporte, comunicación y seguimiento (Martínez, 2009). El estudio concluye que los profesores requieren una formación o alfabetización para que sean capaces de hacer uso de todos estos nuevos recursos, pero principalmente adquirir competencias pedagógicas para utilizar las nuevas tecnologías digitales.

Por lo antes explicado, vemos que, por un lado, puede ser positiva la inclusión de las tecnologías digitales al proceso de enseñanza y aprendizaje, pero, por otro lado, hay evidencias que nos muestran que su inclusión no es tan favorable si el profesor no está preparado.

\section{Problemática}

De acuerdo con Huang et al. (2020), en diciembre del 2019 surgieron varios casos de neumonía debido a causas desconocidas, en la provincia de Wuhan, Hubei, China, con manifestaciones clínicas muy parecidas a la neumonía viral. El análisis de secuenciación profunda de muestras del tracto respiratorio inferior indicó un nuevo coronavirus, que se denominó nuevo coronavirus 2019 (2019-nCoV o COVID-19 en México). Un poco después, más de 800 casos confirmados, incluyendo a trabajadores del área de la salud, fueron 
identificados en Wuhan, y varios casos exportados se fueron confirmando en otras provincias de China, así como en Tailandia, Japón, Corea del Sur, y los Estados Unidos. Posteriormente, se extendió por el mundo y fue declarada pandemia global por la Organización Mundial de la Salud el 11 de marzo del 2020 (OMS). Esto significa que la epidemia se ha extendido por varios países, continentes o todo el mundo, y que afecta a un gran número de personas.

Como consecuencia, el sistema educativo a nivel mundial ha tenido que migrar de la educación presencial a la educación virtual o en línea, de manera obligada. En el caso de México, el 20 de marzo del 2020, la educación quedó paralizada (Hernández, 2020), a partir de esa fecha la SEP empezó a planear la migración de la educación presencial a una no presencial. El 15 de abril del 2020, en su cuenta de Twitter oficial, la SEP anunció que se continuaría la enseñanza y aprendizaje en la modalidad en línea o TV en el nivel básico a partir del 20 de abril del 2020 (Ver Figura 1). Aunque días después se extendió la fecha de inicio hasta el 30 de abril del 2020. De manera análoga, las instituciones educativas de nivel medio superior y superior decidieron migrar a una educación virtual y en línea.

Figura 1: La SEP México, anuncia la continuación de la educación por TV o en línea

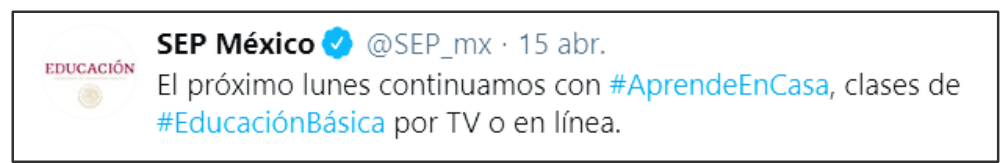

Fuente: Twitter oficial de la SEP

Ante esta circunstancia, todos los niveles educativos tuvieron que hacer la transición obligada, forzando a docentes, alumnos, padres, directivos y en sí a toda la sociedad a realizar de manera apresurada un cambio en la enseñanza-aprendizaje. Tanto profesores como estudiantes tuvieron que modificar su manera de enseñar y su forma de aprender. ¿Pero, realmente estábamos preparados para realizar la transición? ¿Los profesores al menos sí estaban capacitados? Cada autoridad federal, estatal y cada institución educativa han dado una respuesta distinta de cómo darle continuidad a la educación, dando por hecho de que la educación no sufrirá un rezago. Pero se han dado diversas publicaciones que dicen que no estamos preparados y por consiguiente habrá rezago, inequidad, falta de conectividad, falta de tecnología digital, etc. (Estrada, 2020; Mireles, 2020).

Álvarez (2020) menciona que la propuesta de la SEP para continuar con la educación básica, centrada en el continuismo curricular y reproductor de prácticas educativas obsoletas, si 
no han funcionado en modo presencial, menos funcionarán desde los hogares, ya que se tienen brechas digitales y exclusiones educativas. El impulso de la SEP federal junto con las autoridades educativas estatales a la Estrategia de Educación a Distancia: transformación e innovación para México "Propuesta integral frente al COVID-19" generará diversas reacciones y efectos por ser gestionada a través de una plataforma que pertenece a Google, pero, también, tenderá a reproducir las desventajas de la brecha digital. Por otra parte, hay instituciones como la UNESCO y la UNICEF que consideran que la continuidad en México se dará de manera positiva (Azoulay, 2020; Díaz, 2020).

En el caso del nivel medio superior y superior, existen ciertas evidencias de que las instituciones educativas se encontraban preparadas para la transición antes de que se diera la pandemia (Estrada, 2020; Vázquez, 2020), ya que, de hecho, en muchos de esos casos, se aplicaba una metodología híbrida (presencial y en línea). Ante estos dos panoramas, se plantea lo siguiente:

El profesorado de México de los niveles medio superior y superior, ante la epidemia del COVID-19, ¿estaba preparado en el uso de tecnologías digitales, para continuar su trabajo de docencia ante la transición obligada de educación presencial a educación virtual o en línea?

\section{Objetivo general y específicos}

El objetivo de la investigación es obtener evidencias sobre la preparación de los profesores en el uso de las TIC para la práctica docente ante el cambio de enseñanza presencial a virtual o en línea. De aquí se desprenden los siguientes objetivos específicos:

1. Identificar los elementos necesarios de las TIC útiles para la práctica docente.

2. Obtener información de parte de los profesores sobre el uso de las TIC en su práctica docente.

3. Averiguar el conocimiento en el uso de las TIC de parte de los docentes en la migración de enseñanza presencial a virtual o en línea durante la contingencia.

\section{Marco conceptual}

Existen dos maneras de realizar una investigación, con un enfoque cuantitativo o con un enfoque cualitativo. Cada enfoque tiene sus propios fundamentos epistemológicos, su propia 
metodología, sus propias técnicas de investigación, así como la manera de realizar el análisis de la información recabada. Cabe resaltar que estos enfoques no son excluyentes, sino que pueden llegar a ser complementarios cuando por necesidades de la propia investigación es necesario realizar un estudio mixto. De acuerdo con Monje (2011), la metodología cuantitativa se fundamenta en conceptos teóricos con los cuales podemos formular hipótesis a comprobar, y mediante un estudio empírico se pretende validar las hipótesis formuladas. El procedimiento de una investigación cuantitativa se muestra en la Figura 2.

Figura 2: Procedimiento de la investigación cuantitativa

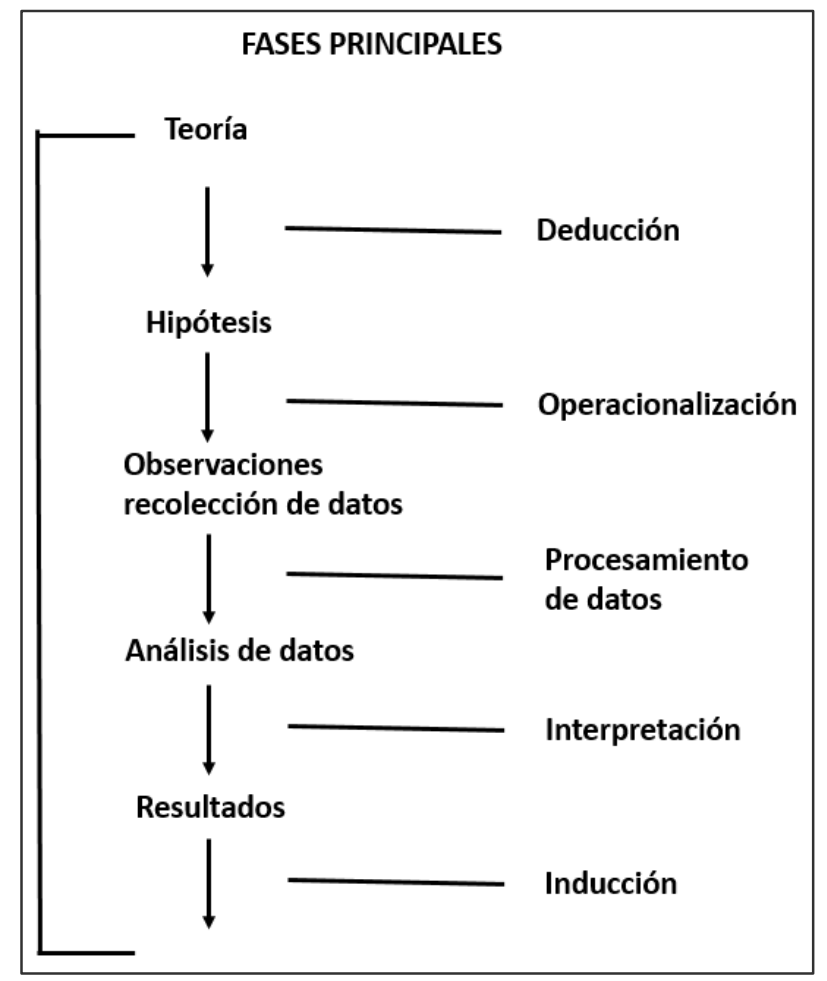

Fuente: Creado a partir de Monje (2011)

La metodología cualitativa en cambio pretende validar sus hipótesis a partir de la apreciación o conocimiento que tiene el individuo de su entorno en estudio. La investigación cualitativa tiene como objetivo la descripción, la explicación o la comprensión del problema en estudio. Mientras que, en la investigación cuantitativa, su objetivo principal es la explicación del fenómeno en observación, por medio de una muestra de la población en estudio, y de ser posible dar una predicción. En la Figura 3, se muestra el procedimiento de una investigación cualitativa. 
Figura 3: Procedimiento de la investigación cualitativa

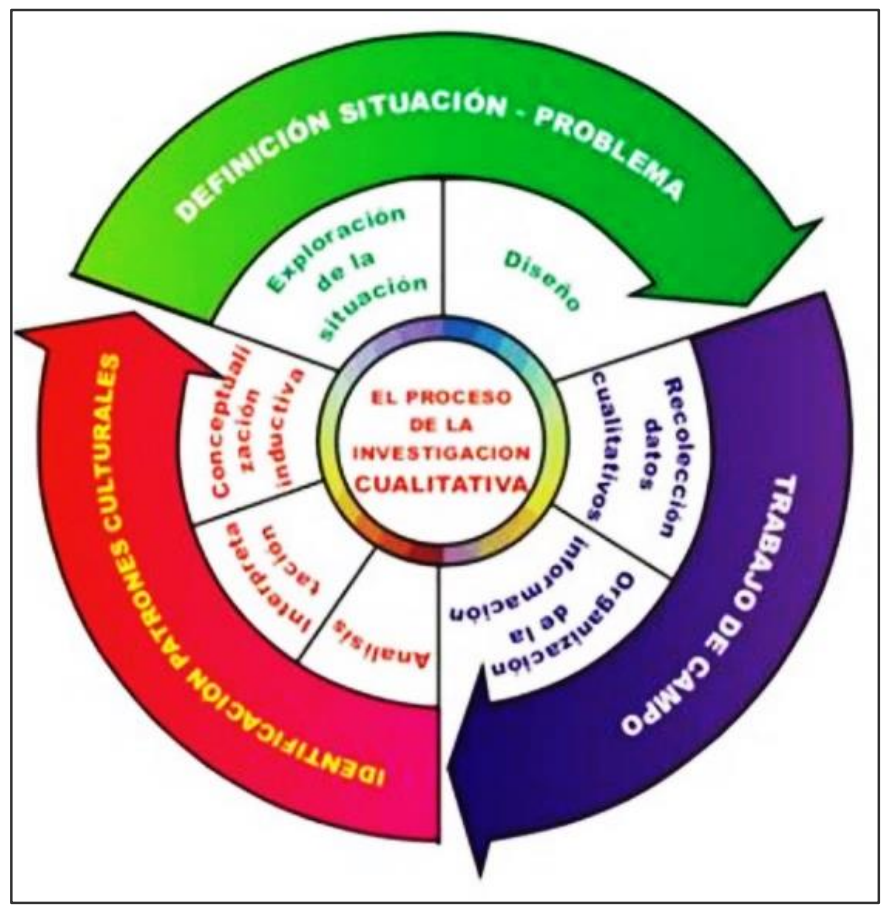

Fuente: Bonilla y Rodríguez (1997, p. 77-103)

Una encuesta según diversos autores (Casas et al., 2002; Montero, 2016; Peersman, 2014) es un método estandarizado muy eficiente para la obtención de información de un grupo de personas a través de una serie de preguntas, si lo que queremos es precisión y representatividad. Hay dos tipos de encuestas: descriptivas o analíticas. Mientras que un cuestionario es la forma de hacer un compendio de información acerca de una persona o grupo de personas, y es común diseñar una serie de preguntas de tal manera que las preguntas sean apropiadas al objetivo planteado. Existen 3 tipos de cuestionarios: abiertos, cerrados o mixtos.

\section{Metodología}

Para el desarrollo de la investigación y la obtención de la información requerida por parte de los docentes, se propone seguir el siguiente orden metodológico de trabajo.

- Diseño del instrumento de investigación tipo encuesta.

- Aplicación del instrumento a docentes del nivel medio superior y superior de México.

- Análisis estadístico de la información obtenida.

- Interpretación de los resultados y conclusiones. 


\section{Diseño y aplicación de instrumento de investigación}

El siguiente objetivo para contestar nuestra pregunta de investigación, fue el diseñar y aplicar un instrumento de investigación que nos permita conocer si en el año 2020 por el motivo de la pandemia del COVID-19, el profesorado de México de los niveles medio superior y superior, se encontraba preparado para la transición del modelo presencial al modelo virtual o en línea, para la continuidad del trabajo de docencia. Después de analizar la situación y tomando en cuenta la dificultad de movilidad, por la cuarentena impuesta por el gobierno federal, para realizar la encuesta, se decide diseñar un cuestionario de tipo mixto en línea, que nos permita obtener la información requerida.

Para la realización y validación del instrumento, de acuerdo con Corral (2009), se creó un cuestionario y se validó en la categoría de validez de contenido, es decir, el análisis del instrumento se hace en gran parte en función de su contenido. La validez de contenido debe ser muy afín a la planificación del cuestionario, y después con la creación de los ítems ajustados a los planes a investigar, así para la validez de contenido se aplicó el juicio de expertos. Se empleó un instrumento con el formato que se propone en Corral (2009). En la validación participaron cuatro expertos investigadores de distintas instituciones educativas (dos expertos en trabajo estadístico, dos expertos de educación matemática), los cuales fueron afinando el cuestionario, finalmente se editó utilizando un formulario de Google Forms ${ }^{1}$. Éste consistió de 24 preguntas, de las cuales dos fueron preguntas abiertas, se subió a Internet, y se empezó a aplicar, para esto se ha hecho la invitación por correo electrónico a diversos profesores de distintas instituciones educativas de nivel medio superior y superior con los que tenemos contacto en México.

Hasta el momento del trabajo, éste contiene la información de 159 profesores de los dos niveles educativos en estudio, aunque hay datos de 18 profesores extranjeros que han contestado, ya que seguimos haciendo la invitación a más profesores, tanto de México como extranjeros, con la finalidad de enriquecer la base de datos y efectuar estudios y resultados más contundentes y comparativos. Como se permitió en algunos ítems que hubiera más de una respuesta, las respuestas se tuvieron que codificar para agruparlas por similitud en alguna

\footnotetext{
${ }^{1}$ El formulario puede ser consultado en: http://forms.gle/kSRzM1SKLBCvdUXy9.
} 
característica de su respuesta. Así que, eliminando en este trabajo a los profesores extranjeros, se presenta el estudio de 141 profesores que involucra a ambos niveles.

\section{Características de los sujetos de la muestra}

Se encuestaron un total de 141 profesores que laboran en la República Mexicana, 63.1\% de la Región Central (Puebla, CDMX, Hidalgo, Tlaxcala, Michoacán, Querétaro), el 35.5\% de la Región Norte (Sinaloa, Durango, Sonora, Nuevo León) y 1.4\% de la Región Sur (Yucatán, Oaxaca) (Tabla 1). Del total, el 68.8\% (97 profesores) imparten clase en el nivel Medio Superior y el 31.2\% (44 profesores) en el nivel Superior (Tabla 1), distribuidos en diferentes tipos de instituciones como son: Telebachillerato Comunitario, Bachillerato, CECYT, Escuela Normal, Preparatoria, Tecnológico, Universidad y Bachillerato digital (Tabla 2). Además, el 61.7\% es del sector público y el $38.3 \%$ del sector privado (Tabla 2).

Tabla 1: Características de la muestra. Región de Origen y Nivel educativo en el que labora

\begin{tabular}{|l|l|r|r|r|}
\cline { 3 - 5 } \multicolumn{2}{c|}{} & \multicolumn{2}{c|}{ Nivel } & \multirow{2}{*}{ TOTAL } \\
\cline { 3 - 5 } \multicolumn{2}{c|}{} & Medio Superior & \multicolumn{1}{|c|}{ Superior } & \\
\hline \multirow{3}{*}{ Región de origen } & Región Central & $47.5 \%$ & $15.6 \%$ & $63.1 \%$ \\
\cline { 2 - 5 } & Región Norte & $20.6 \%$ & $14.9 \%$ & $35.5 \%$ \\
\cline { 2 - 5 } & Región Sur & $0.7 \%$ & $0.7 \%$ & $1.4 \%$ \\
\hline & TOTAL & $68.8 \%$ & $31.2 \%$ & $100 \%$ \\
\hline
\end{tabular}

Fuente: Elaboración propia

Tabla 2: Características de la muestra. Tipo de institución y sector

\begin{tabular}{|l|l|r|r|r|}
\cline { 2 - 4 } \multicolumn{2}{c|}{} & \multicolumn{1}{c|}{ Privado } & \multicolumn{1}{c|}{ Público } & \multicolumn{1}{c|}{ TOTAL } \\
\hline Institución & Bachillerato & $2.8 \%$ & $19.8 \%$ & $22.60 \%$ \\
\cline { 2 - 4 } & Bachillerato Digital & $6.4 \%$ & $7 \%$ & $13.40 \%$ \\
\cline { 2 - 4 } & CECYT & $0 \%$ & $1.41 \%$ & $1.41 \%$ \\
\cline { 2 - 4 } & Escuela Normal & $0 \%$ & $0.7 \%$ & $0.70 \%$ \\
\cline { 2 - 4 } & Preparatoria & $14.18 \%$ & $11.3 \%$ & $25.48 \%$ \\
\cline { 2 - 5 } & Tecnológico & $6.4 \%$ & $2.1 \%$ & $8.50 \%$ \\
\cline { 2 - 5 } & Telebachillerato Comunitario & $0 \%$ & $2.8 \%$ & $2.80 \%$ \\
\cline { 2 - 5 } & Universidad & $8.5 \%$ & $16.3 \%$ & $24.80 \%$ \\
\hline
\end{tabular}

Fuente: Elaboración propia

Identificamos también el área de conocimientos que trabajan (Figura 4) y el mes en que los profesores tuvieron que hacer la transición de educación presencial a educación a distancia, mostrando al mes de marzo como fecha principal (Figura 5). 
Figura 4: Área de enseñanza de los profesores

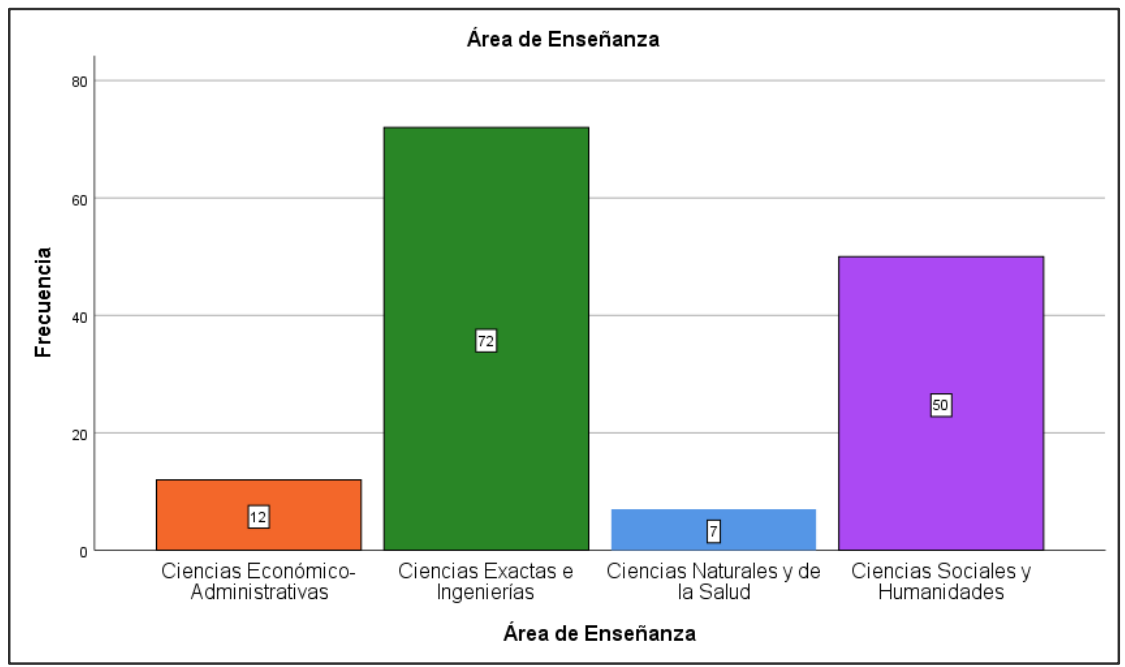

Fuente: Elaboración propia

Figura 5: Transición de educación a distancia

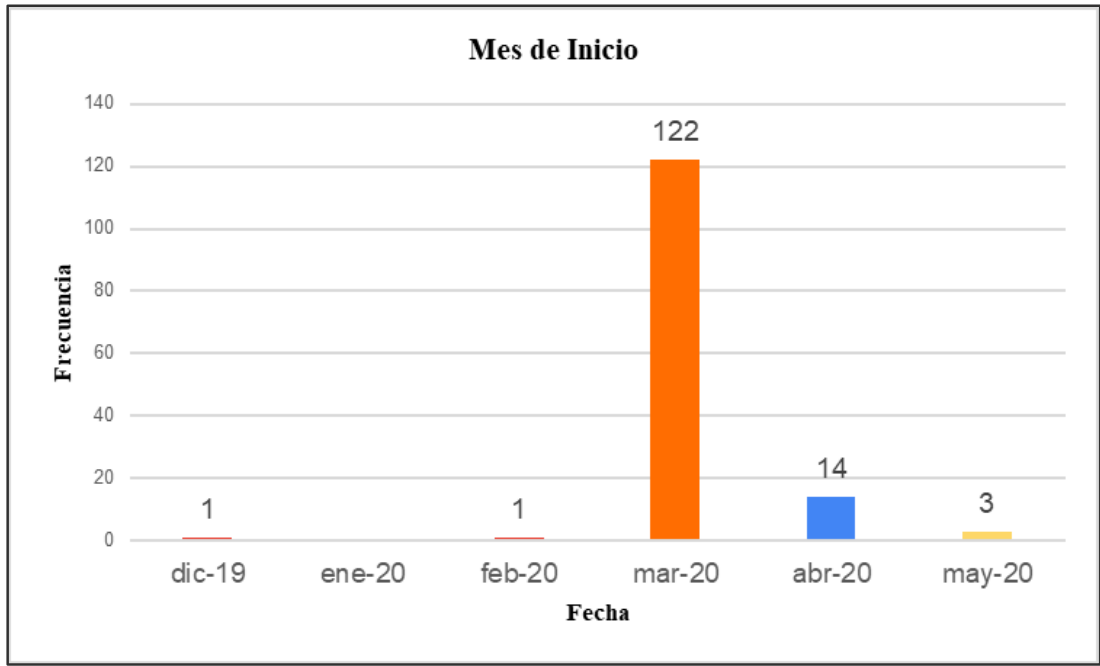

Fuente: Elaboración propia

\section{Análisis de Resultados}

Uno de los aspectos considerados en el estudio, es el tiempo utilizado para la preparación y planeación de las clases, diversas publicaciones (Figueroa, 2020; Ponce 2020) mencionan que la carga de trabajo de los docentes en tiempos de pandemia se ha incrementado significativamente, resultando en una sobrecarga laboral. Para corroborar dicha afirmación, analizamos las respuestas de los docentes y obtuvimos que en promedio, antes de la contingencia, empleaban aproximadamente 6 horas a la semana por asignatura y después se incrementó en promedio a 9.5 horas (Tabla 3), lo que nos lleva a preguntarnos si este incremento 
es significativo, para ello, realizamos una prueba de hipótesis para diferencia de medias, comparando el tiempo utilizado en tiempos normales y durante la contingencia, observamos el estadístico t con su nivel de significación bilateral, este valor nos informa sobre el grado de compatibilidad entre la hipótesis de igualdad de medias y la diferencia entre medias poblacionales observadas; en este caso es casi 0 , lo que nos lleva a rechazar la hipótesis de igualdad.

Tabla 3: Estadísticas del tiempo empleado antes y durante la contingencia

\begin{tabular}{|l|r|r|r|r|}
\cline { 2 - 5 } \multicolumn{1}{c|}{} & Media & $\mathrm{N}$ & \multicolumn{1}{c|}{$\begin{array}{c}\text { Desv. } \\
\text { Desviación }\end{array}$} & $\begin{array}{c}\text { Desv. Error } \\
\text { promedio }\end{array}$ \\
\hline Tiempo dedicado durante la contingencia & 9.4555 & 141 & 8.36051 & .70408 \\
\hline $\begin{array}{l}\text { Tiempo dedicado antes de la } \\
\text { contingencia }\end{array}$ & 5.816 & 141 & 5.0042 & .4214 \\
\hline
\end{tabular}

Fuente: Elaboración propia

Podemos observar también los límites de confianza para la diferencia, que están entre 2.26 y 5.01 horas, el hecho de que el 0 no esté incluido, indica que podemos rechazar la hipótesis de igualdad, en resumen y debido a que la media de las horas empleadas durante la contingencia es mayor, confirmamos con un nivel de confianza de casi $100 \%$ que el tiempo empleado por los docentes aumentó de manera considerada (Tabla 4).

Tabla 4: Prueba de hipótesis de diferencia de medias del Tiempo dedicado durante la contingencia -

Tiempo dedicado antes de la contingencia

\begin{tabular}{|c|c|c|c|c|c|c|c|}
\hline \multirow[b]{3}{*}{ Media } & \multicolumn{6}{|c|}{$\begin{array}{c}\text { Prueba de } \\
\text { Diferencias emparejadas }\end{array}$} & \multirow{3}{*}{$\begin{array}{c}\text { Sig. } \\
\text { (bilateral) }\end{array}$} \\
\hline & \multirow{2}{*}{$\begin{array}{c}\text { Desv. } \\
\text { Desviación }\end{array}$} & \multirow{2}{*}{$\begin{array}{c}\text { Desv. Error } \\
\text { promedio }\end{array}$} & $\begin{array}{l}99 \% \text { de in } \\
\text { confianza de }\end{array}$ & $\begin{array}{l}\text { valo de } \\
\text { diferencia }\end{array}$ & \multirow[b]{2}{*}{$\mathrm{t}$} & \multirow[b]{2}{*}{ gl } & \\
\hline & & & Inferior & Superior & & & \\
\hline 3.63922 & 6.23355 & .52496 & 2.26834 & 5.01010 & 6.932 & 140 & .000 \\
\hline
\end{tabular}

Fuente: Elaboración propia

Debido a la necesidad de hacer uso de herramientas digitales para la transición de educación presencial a en línea, indagamos acerca de cuántas y cuáles de dichas herramientas ya conocían y a qué nivel, cuántas y cuales tuvieron que aprender y finalmente cuántas y cuáles terminaron utilizando, resultados que se muestran en las Figuras 6-11.

La Figura 6, nos muestra que la mayoría de los docentes conocían entre 4 y 7 herramientas, aunque existen profesores que conocían más de 10. 
Figura 6: Cantidad de herramientas digitales utilizadas

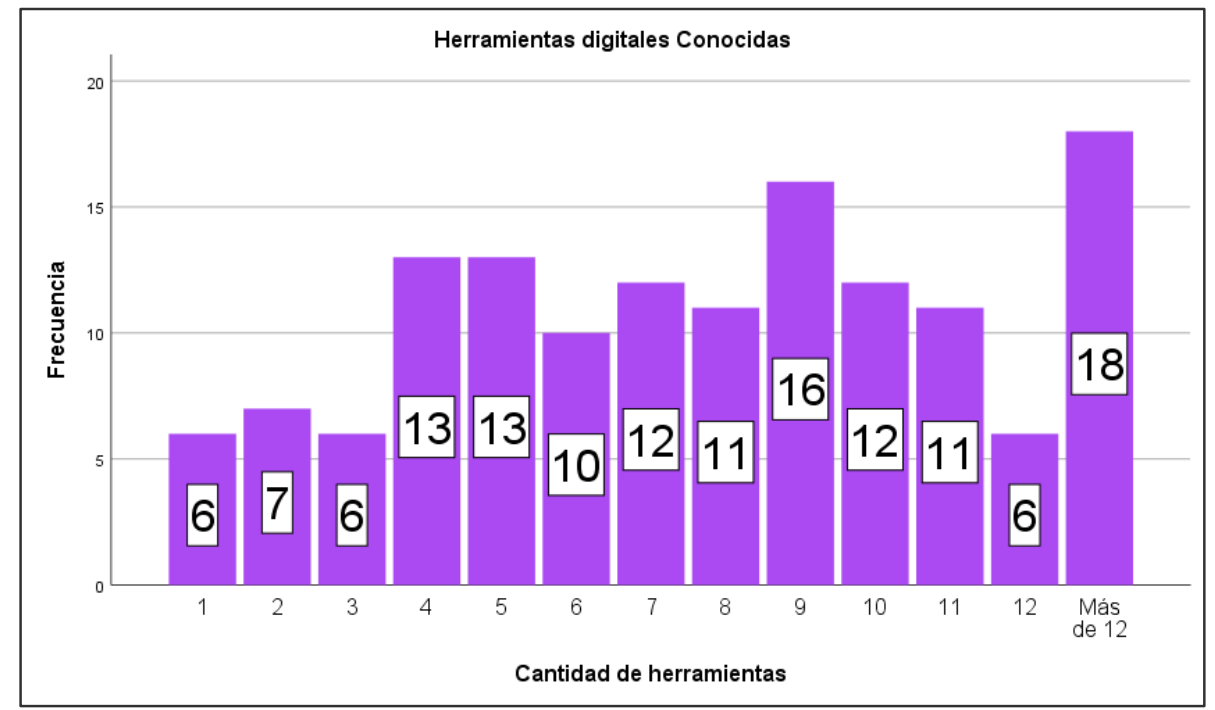

Fuente: Elaboración propia

La Figura 7, nos dice que gran parte de los docentes (41.13\%) consideran que el nivel de dominio de las herramientas que ya conocen es de más del $75 \%$.

Figura 7: Nivel de Dominio

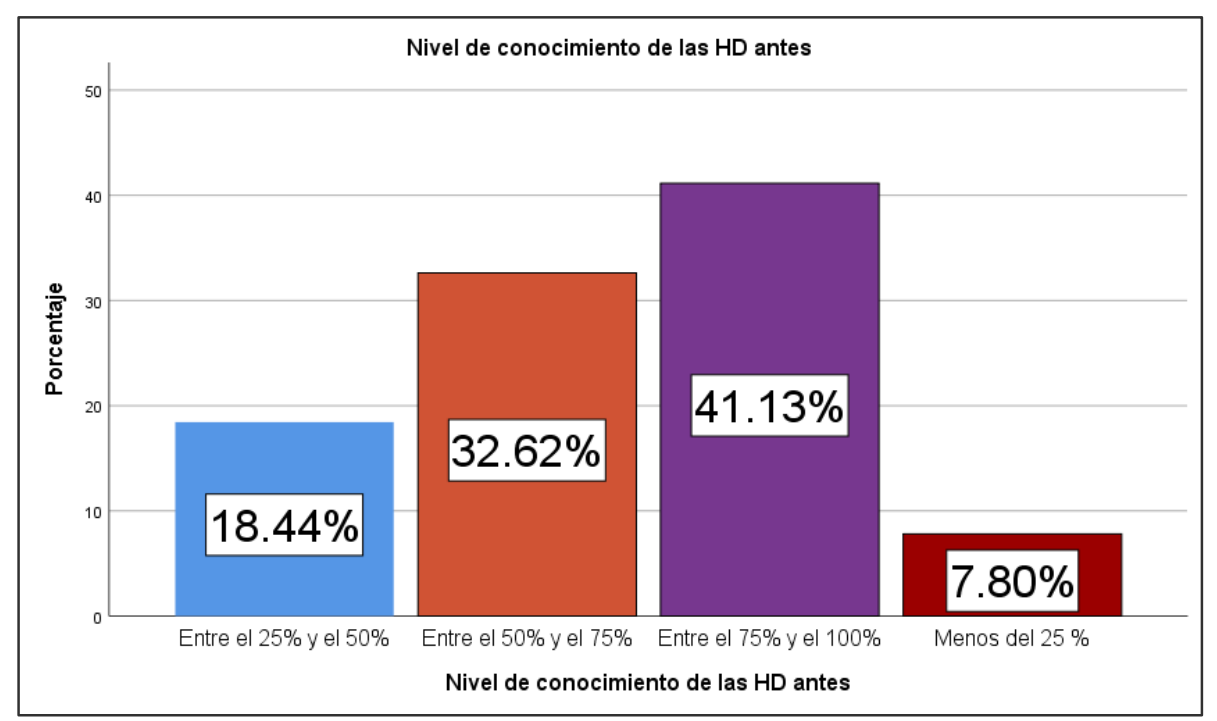

Fuente: Elaboración propia

Entre las herramientas más conocidas están Facebook, WhatsApp, Correo Electrónico, Messenger y Google Drive, en resumen, las que se han utilizado sólo para la comunicación y repositorio de material (Figura 8). 
Figura 8: Tipos de herramientas conocidas

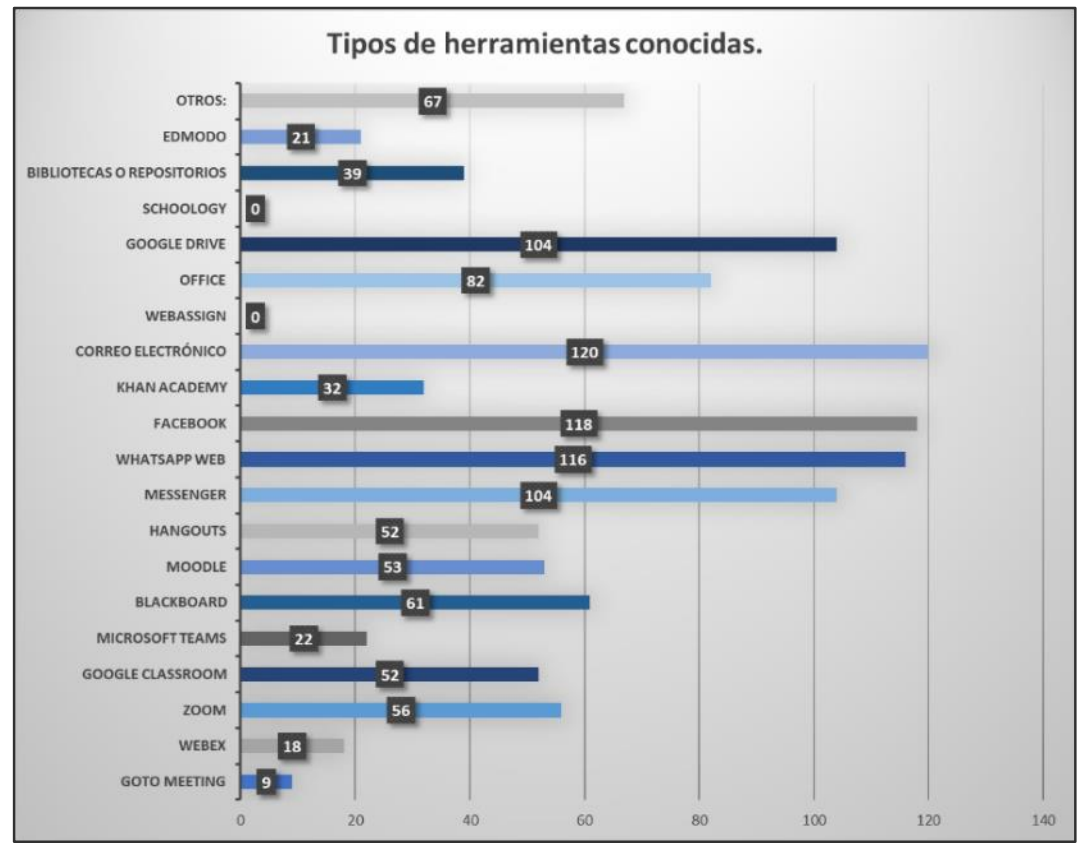

Fuente: Elaboración propia

Sin embargo, también estas fueron aprendidas por otros profesores, junto con Zoom y Google Classroom (Figura 9), para finalmente concretar las clases principalmente con Schoology, WhatsApp, Bibliotecas, Google drive, Google Classroon, Facebook y otros en pequeñas proporciones que incluyen Skype, Geogebra, Youtube, Canvas, etc. (Figura 10).

Figura 9: Tipo de herramientas aprendidas

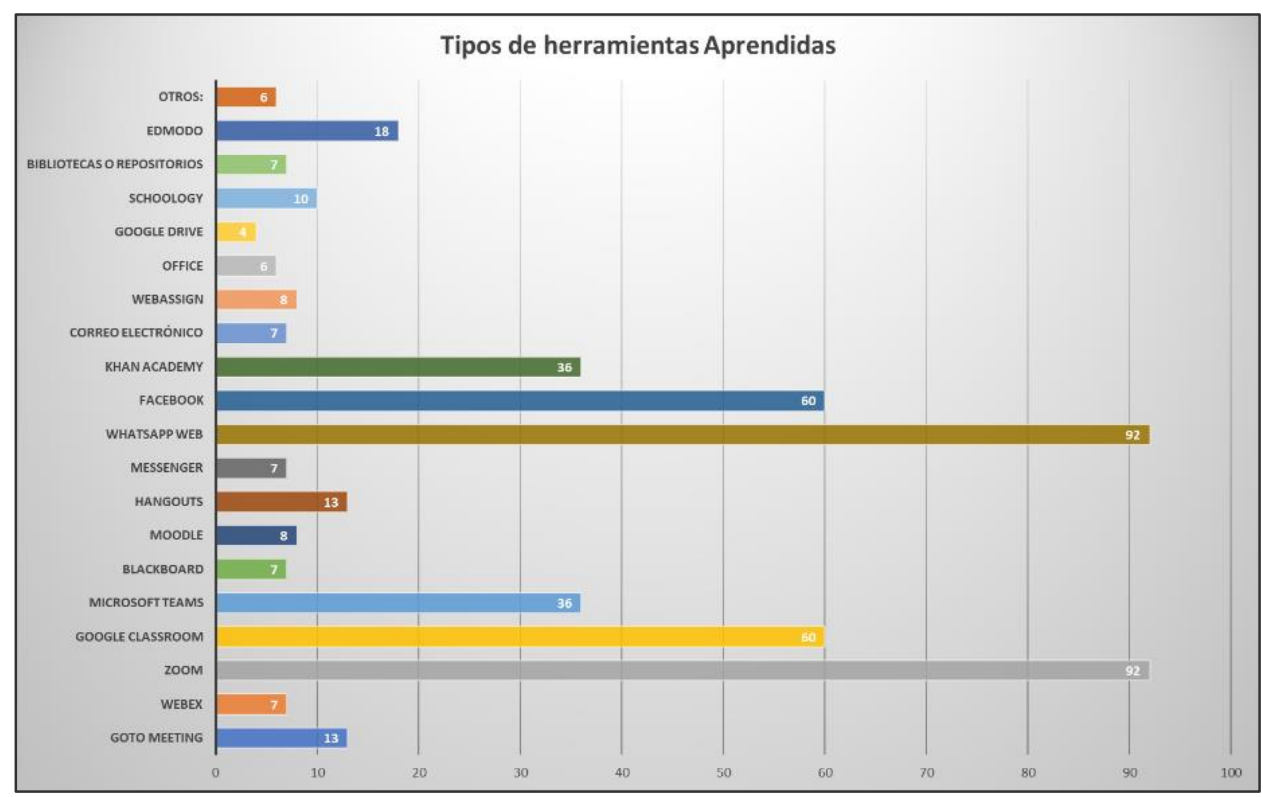

Fuente: Elaboración propia 
Figura 10: Tipos de herramientas utilizadas

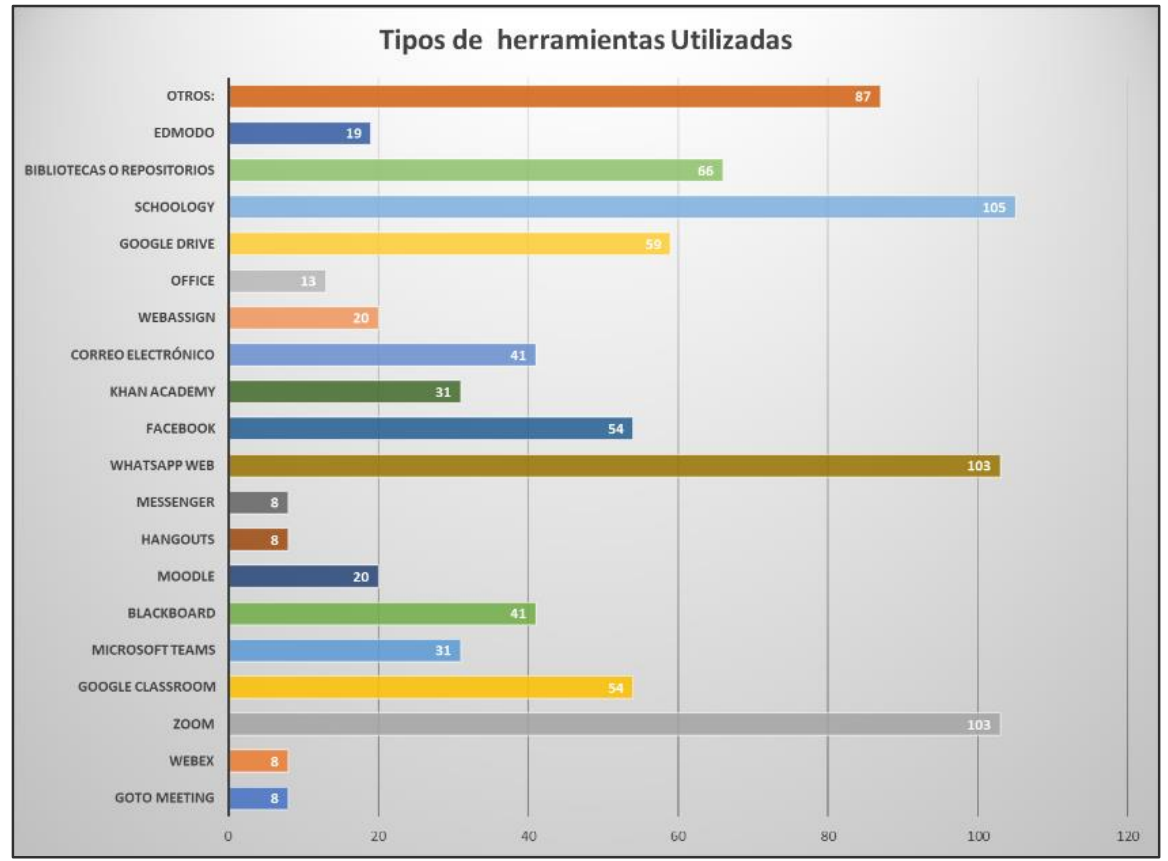

Fuente: Elaboración propia

En promedio, el docente utiliza alrededor de 6 herramientas digitales para sus clases (Figura 11), siendo el WhatsApp y el correo electrónico el medio principal de comunicación (Figura 12).

Figura 11: Cantidad de herramientas aprendidas y utilizadas

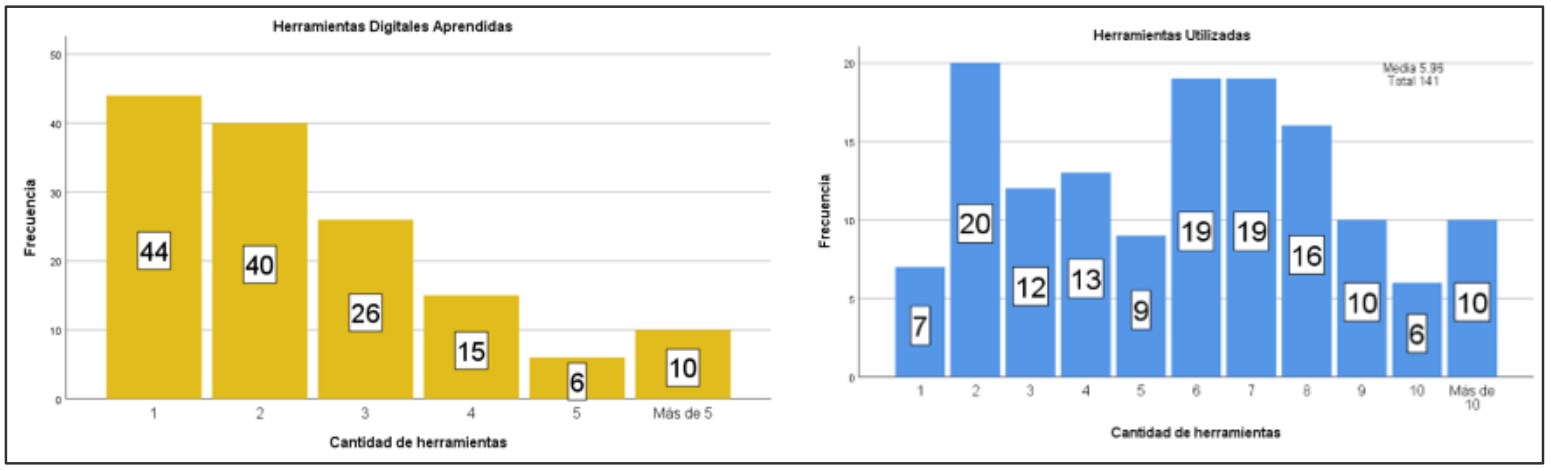

Fuente: Elaboración propia 
Figura 12: Medio de Comunicación Principal

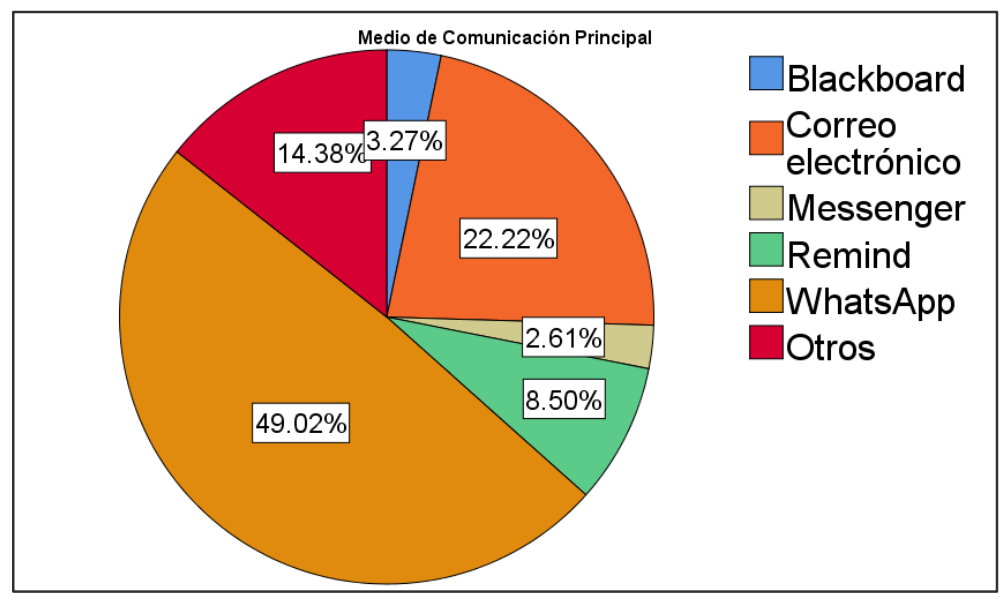

Fuente: Elaboración propia

Exploramos sobre los recursos utilizados en las clases a distancia, así como los que podrían mejorar o facilitar el trabajo pero que no cuentan actualmente con ellos. Mostrando que además de un equipo de cómputo e Internet, la mayoría hace uso de una cámara de video, diadema con micrófono, impresora, pizarrón normal o digital y escáner principalmente, y curiosamente observamos que el teléfono celular no está en esta lista (Figura 13).

Figura 13: Recursos Utilizados

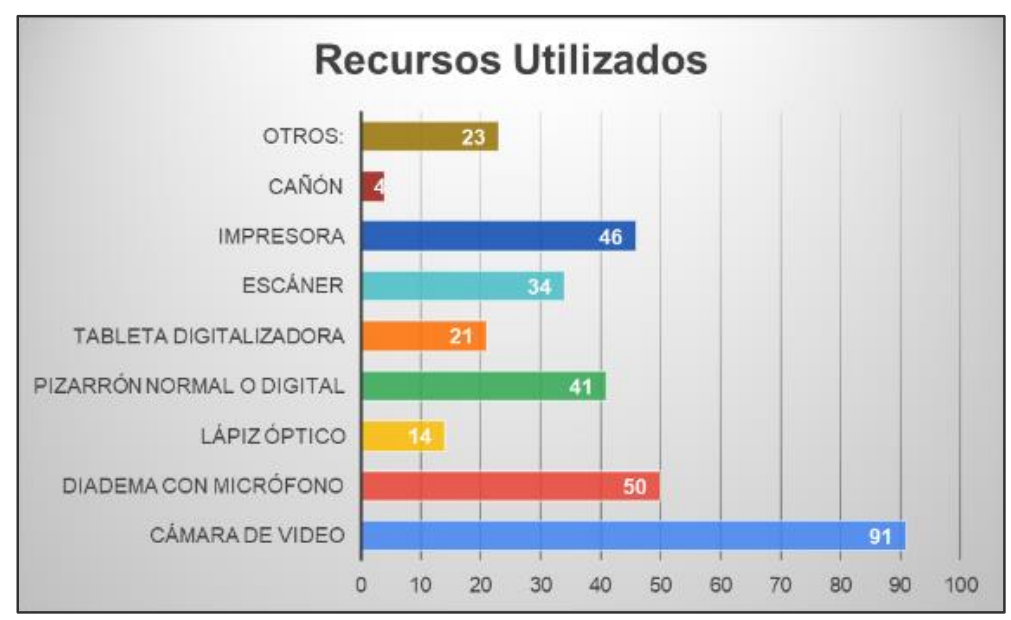

Fuente: Elaboración propia

Sin embargo, una tarjeta digitalizadora y el pizarrón para los que no lo tienen que facilitaría la transmisión y explicación de los temas como en la clase presencial, por lo que manifiestan sería un recurso que los ayudaría en sus clases (Figura 14). 
Figura 14: Recursos Adicionales

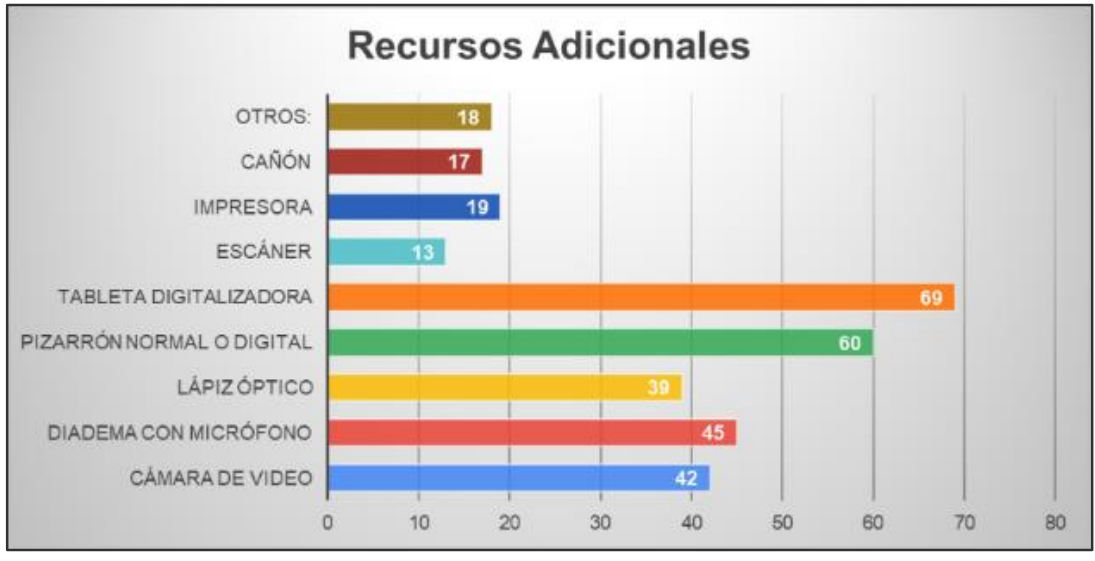

Fuente: Elaboración propia

Es importante también, conocer las estrategias que los profesores han llevado a cabo para la impartición de las clases, las evaluaciones y la retroalimentación ahora en esta nueva modalidad. El estudio muestra que la principal estrategia es el uso de diapositivas (95) y lecturas (92), pero también se han seguido las clases a través de videos (88) asesorías por video llamadas (66) y clases en vivo (74), dejando en otras: Actividades, problemas, asesorías por WhatsApp, etc. (Figura 15).

Figura 15: Estrategias de impartición de clases

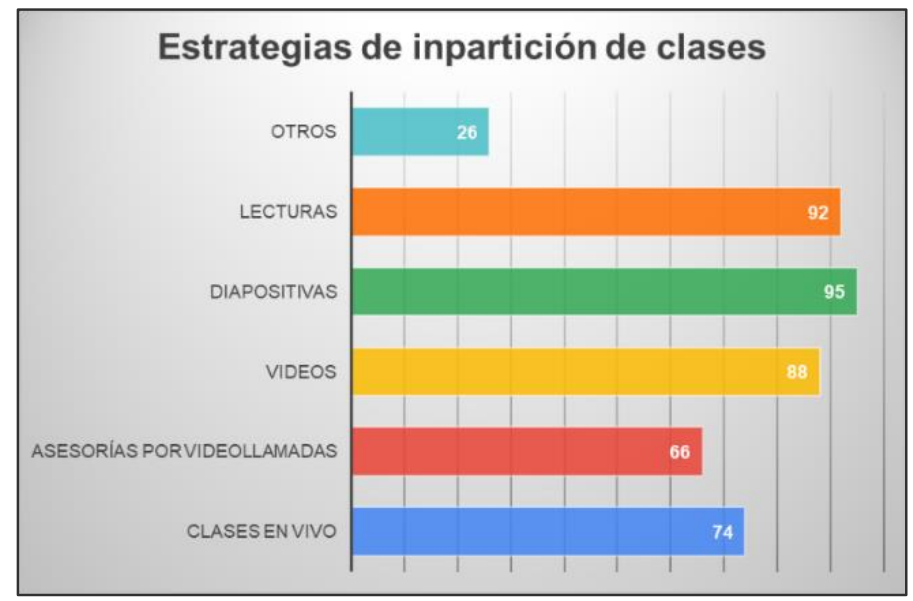

Fuente: Elaboración propia

En cuanto a las evaluaciones, se destaca la elaboración de proyectos, las entregas de actividades cronometradas y los exámenes realizados en plataformas digitales y se muestra como otras alternativas aisladas el trabajo en grupos, actividades en plataforma, etc. (Figura 16). 
Figura 16: Tipos de evaluaciones

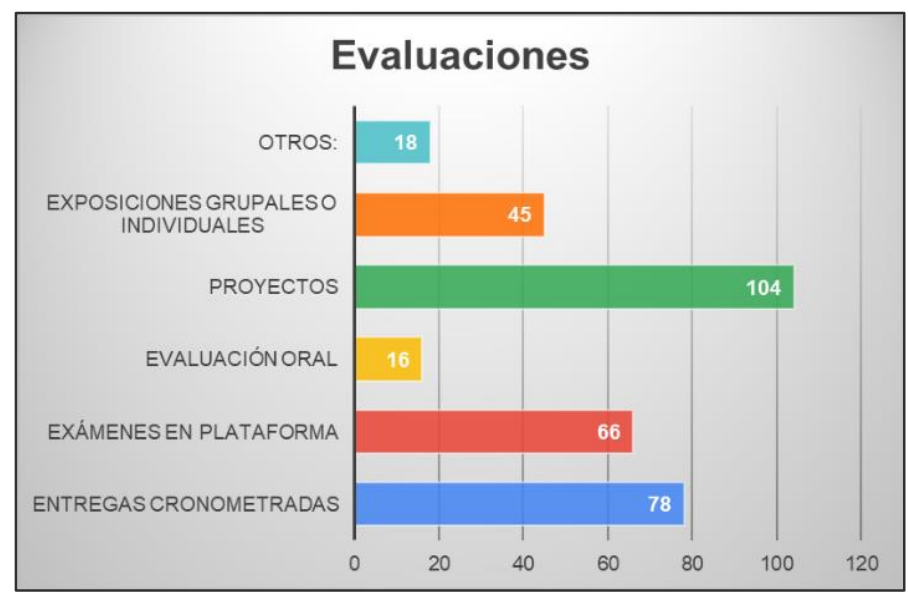

Fuente: Elaboración propia

Para el caso de la retroalimentación y seguimiento del trabajo de los estudiantes, la estrategia más popular es la de mensajes personalizados directamente al estudiante, así como de manera digital en sus documentos de entrega, dejando en otros: los foros, debates, video llamada, videos explicativos, etc. (Figura 17).

Figura 17: Retroalimentación

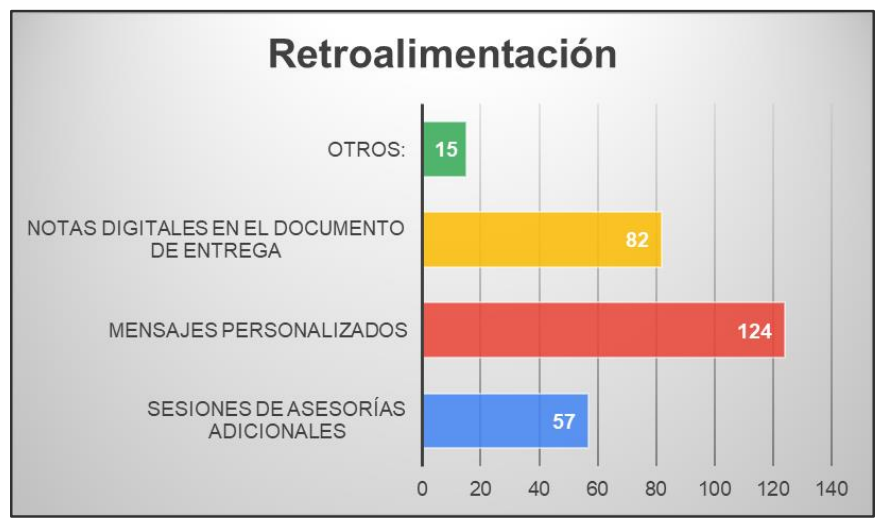

Fuente: Elaboración propia

A pesar de haber sacado adelante a sus grupos, las dificultades siempre se hacen presente, entre las que más destacan son la falta de internet, el incremento en el tiempo utilizado para preparar las clases, el desconocimiento de las redes, entre otros, pero además, los profesores manifiestan otro tipo de dificultades, como son: El cansancio físico / emocional del cambio de rutina, las fallas en el internet, baja velocidad del internet, no poder colaborar de forma presencial, el desinterés de los alumnos y padres de familia, la adecuación de dinámicas de clases (Figura 18). 
Figura 18: Dificultades

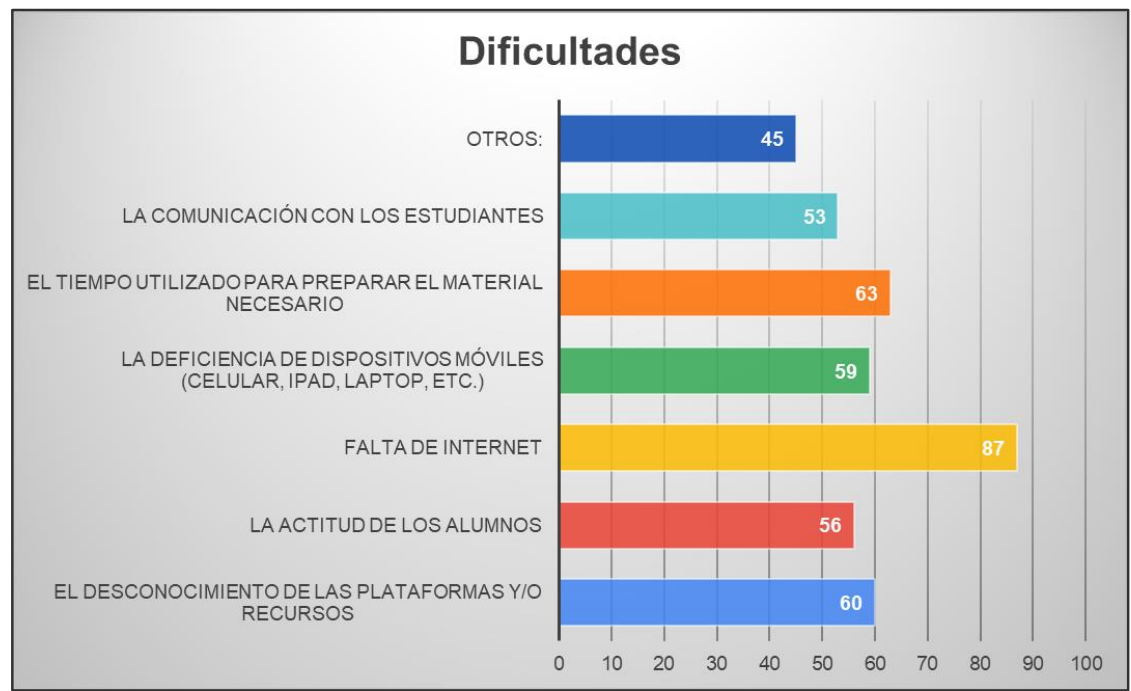

Fuente: Elaboración propia

Al identificar las dificultades expuestas por los profesores los cuestionamos sobre cuáles cursos consideran les sería útil como parte de su capacitación docente para afrontar mejor esta nueva modalidad, el resultado se muestra en la Figura 19.

Figura 19: Cursos de capacitación propuestos

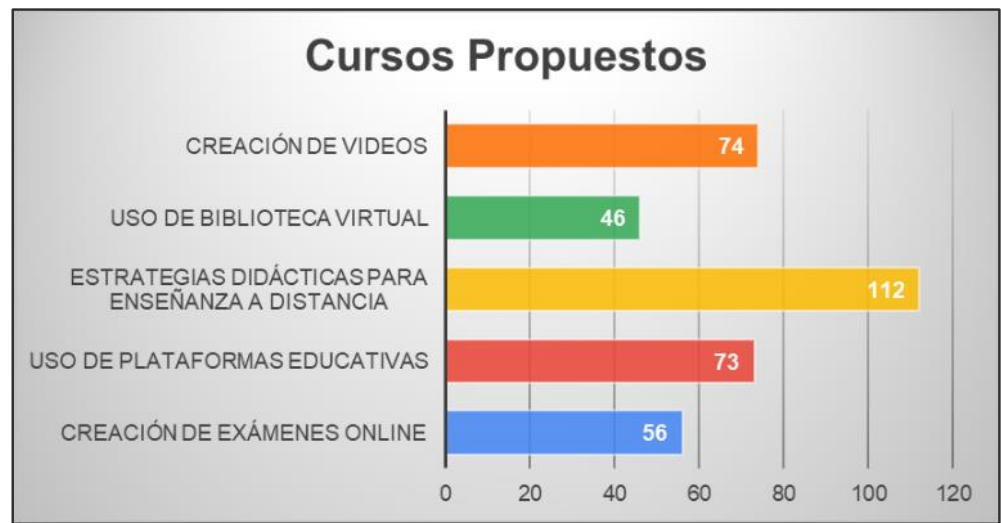

Fuente: Elaboración propia

Finalmente, y con la experiencia vivida, los cuestionamos acerca de su sentir en la nueva modalidad en su nivel de adaptación al cambio, mostrando que un 47\% lo hizo de manera rápida, y sólo el 3,47\% manifestó que no se logró adaptar (Figura 20). Por otro lado, la mayoría de los profesores consideraron que, en sus futuros cursos presenciales, incorporarán de manera más amplia las herramientas digitales (Figura 21). 
Figura 20: Nivel de adaptación al cambio de educación presencial a distancia

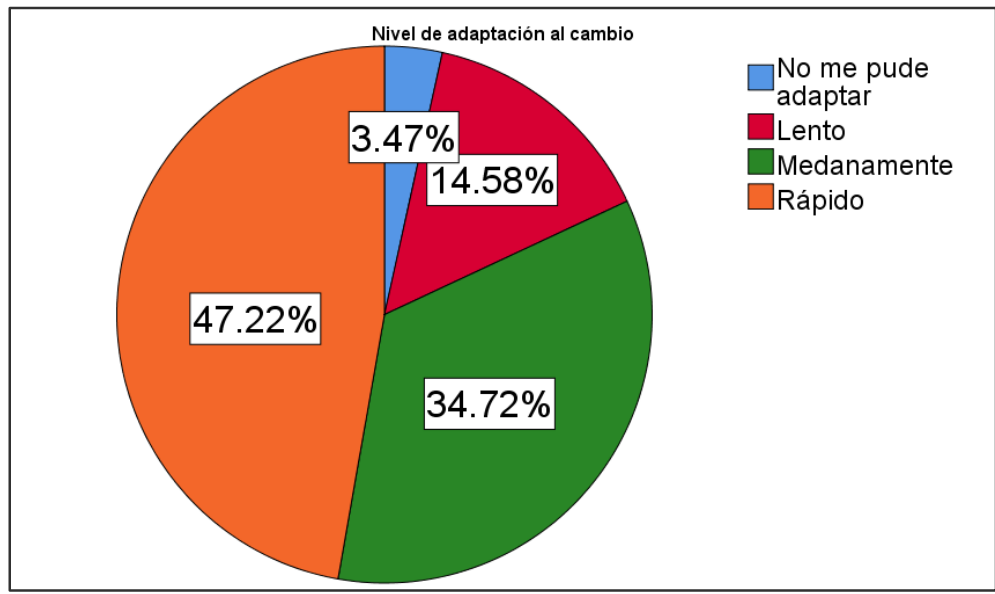

Fuente: Elaboración propia

Figura 21: Incorporación de las herramientas digitales

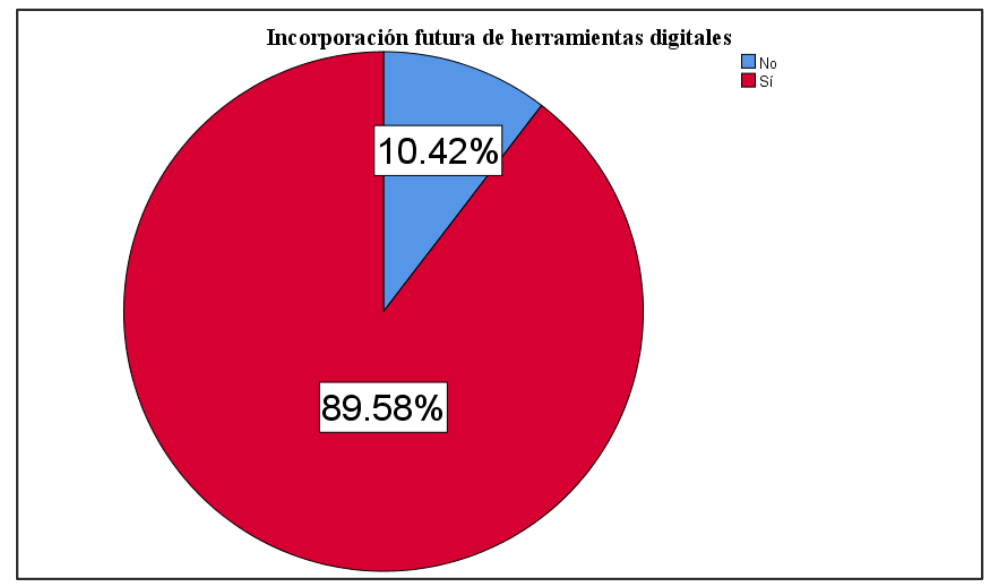

Fuente: Elaboración propia

Respecto a esta última pregunta, se les preguntó, el ¿por qué?, como la pregunta fue abierta, hubo una diversidad de opiniones, pero varias coincidían, aunque con diferentes palabras, así que concentramos las opiniones más representativas:

- Una mayoría argumenta que les son útiles, pues les facilita el trabajo.

- Otro grupo de profesores menciona que es inevitable la transición.

- Un grupo más dijo que es conveniente porque alientan a los estudiantes a también aprender las nuevas tecnologías.

- Unos más mencionan que es por necesidad.

- Hubo profesores que nos dijeron que ya utilizaban las herramientas digitales desde hace tiempo, por lo que no es problema la transición. 
- Finalmente hubo un grupo de profesores (los menos), que mencionó diferentes razones del porqué no. Porque es temporal, porque sus cursos tienen teoría abstracta, porque consideran que el trabajo presencial es mejor, porque donde labora no se tiene la infraestructura, porque el tiempo y contenido no lo permite.

\section{Conclusiones}

Atendiendo a la pregunta de investigación, de acuerdo con Martínez (2009), el profesor se considera capacitado en el uso de las tecnologías en su labor docente si él las utiliza como: recurso didáctico, recurso de soporte, comunicación y seguimiento.

Herramientas tecnológicas como: Facebook, WhatsApp, correo electrónico, Google Drive, fueron las más conocidas por los docentes previo a la contingencia, pero nunca las habían usado de manera intensiva, cabe resaltar que para enfrentar el reto de trabajar virtualmente o en línea, una mayoría se capacitó en herramientas como Zoom, Khan Academy, WhatsApp Web, Google Classroom, Facebook y Microsoft Team, aunque la mitad de los encuestados se capacitó en a lo más 2 herramientas tecnológicas, lo que refleja que solamente buscaron el cómo seguir dando clases como si fuera presencial por medio de alguna aplicación (Zoom la más usada), de igual manera, es relevante la manera en que se diversificó la forma de evaluar, de los exámenes orales y escritos que usualmente eran los de mayor peso, ahora destacaron, las evaluaciones por proyectos, entrega de tareas cronometradas, exámenes en plataforma y exámenes grupales e individuales.

Del mismo modo se modificó la manera de dar asesorías, destacando el uso de mensajes personalizados, notas digitales en el documento de entrega y sesiones virtuales de asesorías adicionales. Todas las dificultades que han presentado son importantes, las que destacaron un poco más fueron, falta de Internet, tiempo para preparar el material necesario, el desconocimiento de las plataformas y/o recursos digitales. Por lo anterior, consideramos que el profesor no se encontraba capacitado en el uso de las tecnologías en su labor docente, y solo utilizó las herramientas digitales como recurso de comunicación (Zoom y WhatsApp), pero casi no como recurso didáctico, de soporte y seguimiento; sin embargo, buscó tener una capacitación, aunque algo improvisada, aun así, consideramos que queda un gran camino por recorrer en cuanto a preparación se trata. 
Podemos finalizar diciendo que, ante la incertidumbre, la mayoría de los profesores (más del 90\%) considera que debe estar preparado en el conocimiento de las tecnologías digitales, ante cualquier circunstancia, con el propósito de evitar que la educación sufra un rezago. Como trabajo a futuro, se tiene contemplado conocer ahora el punto de vista de los estudiantes que son la otra cara de la transición, ya se trabaja en el instrumento de investigación que nos permitirá saber que tan difícil les fue la transición de educación presencial a la educación virtual o en línea.

\section{Referencias}

Adell, J. (1997). Tendencias en educación en la sociedad de las tecnologías de la información. Edutec-e. Revista Electrónica de Tecnología Educativa, 7, artículo a007. https://www.edutec.es/revista/index.php/edutec-e/article/view/570/299

Álvarez, G. (2020). El COMIE y su papel en el conocimiento de los efectos del Covid-19 sobre la educación. Consejo Mexicano de Investigación Educativa A. C. http://www.comie.org.mx/v5/sitio/2020/04/16/covid-19-cambiar-de-paradigmaeducativo/

Azoulay, A. (2020). Destaca UNESCO trabajo de México en materia de educación a distancia durante contingencia sanitaria. Boletín No. 94. Secretaría de Educación Pública https://www.gob.mx/sep/es/articulos/boletin-no-94-destaca-unesco-trabajo-de-mexicoen-materia-de-educacion-a-distancia-durante-contingencia-sanitaria?idiom=es

Bonilla, E., \& Rodríguez, P. (1997). Más allá del dilema de los métodos. La investigación en ciencias sociales ( $3^{\mathrm{a}}$ Ed.). Ediciones Uniandes.

Brousseau, G. (2006). Theory of didactical situations in mathematics: Didactique des mathématiques, 1970-1990 (Vol. 19). Springer Science \& Business Media.

Casas, J., Repullo, J. R. \& Donado, J. (2003). La encuesta como técnica de investigación. Elaboración de cuestionarios y tratamiento estadístico de los datos (I). Atención Primaria, 31(8):527-38.

Corral, Y. (2009). Validez y confiabilidad de los instrumentos de investigación para la recolección de datos. Revista Ciencias de la Educación, 19(33), 228-247.

Díaz, U. (2020). COVID-19: UNICEF llama a la continuidad educativa ante medidas de contingencia. UNICEF. https://www.unicef.org/mexico/comunicados-prensa/covid-19unicef-llama-la-continuidad-educativa-ante-medidas-de-contingencia

Estrada, P. (2020). El aprendizaje remoto enfrenta otro reto: el profesorado no está preparado para la enseñanza en línea. Observatorio de Innovación Educativa. https://observatorio.tec.mx/edu-news/profesorado-no-esta-preparado-para-educaciononline 
Figueroa, A. (2020). Los docentes, la cuarentena y la sobrecarga de las clases a distancia. Página 12. https://www.pagina12.com.ar/263725-los-docentes-la-cuarentena-y-lasobrecarga-de-las-clases-a-d

Gallardo, S. C. H. (2007). El constructivismo social como apoyo en el aprendizaje en línea. Apertura, 7(7), 46-62.

Guaña, E. J., Valencia, J. C., Topón, D. R. \& Pérez, M. A. (2016). El analfabetismo digital en docentes limita la utilización de los EVEA. Revista Publicando, 3(8), pp: 24-36

Hernández, L. (2020). Coronavirus y educación. La Jornada. https://www.jornada.com.mx/2020/04/14/opinion/018a1pol

Huang, C., Wang, Y., Li, X., Ren, L., Zhao, J., Hu, Y., ... \& Cheng, Z. (2020). Clinical features of patients infected with 2019 novel coronavirus in Wuhan, China. The lancet, 395(10223), 497-506.

INEGI. (2020). En México hay 80.6 millones de usuarios de internet y 86.5 millones de usuarios de teléfonos celulares: ENDUTIH 2019. Instituto Federal de Comunicaciones. https://www.inegi.org.mx/contenidos/saladeprensa/boletines/2020/OtrTemEcon/END UTIH_2019.pdf

Noticias Universia. (2020). Carreras en línea: todo sobre la formación online. Universia. En: https://noticias.universia.net.mx/vida-universitaria/noticia/2013/09/25/1051933/sepofrece-13-carreras-online-gratuitas.html

Marquéz, P. (2001). Ideas para aprovechar el ciberespacio en educación. Recuperado el 15 de febrero de 2005 de http://dewey.uab.es/pmarques/buenidea.htm

Martínez, M. (2009). Competencias, Orientación y TIC. Educaweb. http://www.educaweb.com/noticia/2009/02/09/competencias-orientacion-tic$\underline{13467 . h t m l}$

Mireles, A. (2020). El coronavirus pone a prueba el sistema educativo de México: más de la mitad de los estudiantes no tiene acceso a la educación en línea. Infobae. https://www.infobae.com/america/mexico/2020/04/19/el-coronavirus-pone-a-pruebael-sistema-educativo-de-mexico-mas-de-la-mitad-de-los-estudiantes-no-tiene-accesoa-la-educacion-en-linea/

Mirete, A. (2010). Formación docente en TICS. ¿Están los docentes preparados para la (r)evolución TIC? International Journal of Developmental and Educational Psychology, 4 (1), 35-44.

Montero, E. (2016). Recomendaciones para analizar datos basados en encuestas. Abierto al público. Banco Interamericano de Desarrollo. https://blogs.iadb.org/conocimientoabierto/es/recomendaciones-para-analizar-datos-basados-en-encuestas/

Monzón, E. M. (2020). Alfabetización digital en el aula. II Congreso Interuniversitario sobre Educación Virtual (Digital World Learning) (CIEV2019). Pp. 89-98. Universidad Galileo, Guatemala. En: http://biblioteca.galileo.edu/tesario/handle/123456789/960

Monje, C. A. (2011). Metodología de investigación cuantitativa y cualitativa. Guía didáctica. Universidad Surcolombiana. 
OMS. (2020). La OMS caracteriza a COVID-19 como una pandemia. Organización $\begin{array}{llll}\text { Panamericana de la } & \text { Salud. }\end{array}$ https://www.paho.org/arg/index.php?option=com_content\&view=article\&id=10436:1a -oms-caracteriza-a-covid-19-como-una-pandemia\&Itemid=226

Peñate, L. M. (2020). Todos Somos Importantes, pero el Docente es Imprescindible. Revista Internacional de Educación para la Justicia Social, 9(3), 1-4.

Peersman, G. (2014). Sinopsis: Métodos de recolección y análisis de datos en la evaluación de Impacto. Síntesis metodológica n. ${ }^{\circ} 10$, Centro de Investigaciones de UNICEF. https://www.unicef-irc.org/publications/pdf/brief_10_data_collection_analysis_spa.pdf

Ponce, R. (4 de mayo de 2020). Migración digital en cinco pasos. Recuperado el 10 de mayo de 2020 de https://observatorio.tec.mx/edu-bits-blog/migracion-digital-en-cinco-pasos

Redacción (2020). Confirman el primer caso de coronavirus en México. BBC News Mundo. https://www.bbc.com/mundo/noticias-america-latina-51677751

Suárez, J. M. \& Anaya, D. (2004). Educación a distancia y presencial educación a distancia y presencial: diferencias en los componentes cognitivo y motivacional de estudiantes universitarios. RIED. Revista iberoamericana de educación a distancia, 7(1-2), 65-75.

Vázquez, J. C. (2020). Formación transversal en tiempos de COVID-19. Observatorio de Innovación Educativa. https://observatorio.tec.mx/edu-bits-blog/formacion-transversalen-tiempos-de-covid19

Zipitría, S. (2020). El rol del estudiante como diseñador de contenidos. Electronic Journal of SADIO (EJS), 19(2), 151-166.

Autores

José Dionicio Zacarias Flores

Doctor en Ciencias, especialidad Matemática Educativa. Profesor Investigador en la Facultad de Ciencias Físico Matemáticas, de la Benemérita Universidad Autónoma de Puebla. Líneas de Investigación: Probabilidad, Estadística, Matemática Educativa. E-mail: jzacarias@fcfm.buap.mx

Gladys Denisse Salgado Suárez

Doctora en Ciencias (Matemáticas). Profesora en el Departamento de Actuaría, Física y Matemáticas de la Universidad de las Américas Puebla. Líneas de Investigación: Probabilidad, Estadística, Matemática Educativa. E-mail: gladys.salgado@udlap.mx 